\title{
Analysis and Classification of Modern Methods of Ecological Normalization of Anthropogenic Load: Russia vs. the West
}

\author{
Jan Stenis ${ }^{1}$, Mikhail Romanov ${ }^{2}$ and William Hogland ${ }^{1} *$ \\ ${ }^{1}$ The School of Natural Sciences, Linnaeus University SE-391 82 Kalmar, Sweden \\ ${ }^{2}$ Department of Civil Engineering and Applied Ecology St. Petersburg State Polytechnical University Polytehnicheskaya \\ 29, Saint-Petersburg, 195 251, Russia
}

\begin{abstract}
An overview of the classification of ecological normalization methods is presented to facilitate the evaluation of alternatives. An historical review is given of the development of several ecological normalization methods such as Life Cycle Assessment and the International Organization for Standardization's Eco-Management and Audit Scheme and the like in the former Union of Soviet Socialist Republics (USSR), in the European mainland and in the United States of America. Mathematical models together with medical laboratory experiments were generally used in the former USSR to establish pollution permission levels, whereas environmental management tools are more emphasized in the Western world as ecological normalization methods for firms. Perspectives on the future development of these methods are given. It is concluded that the application of methods for ecological normalization is one of the most efficient ways of managing environmental matters today and this promotes human health protection. It is also concluded that the movement towards an increasing accord in quality standards among various countries using a complex approach will result in the continuous development of ecological normalization methods.
\end{abstract}

Keywords: Anthropogenic load, Ecological normalization, Emission standards, Historical review and future development, Russia, The West.

\section{INTRODUCTION}

Ecology politics becomes prominent if the condition of the environment is regarded as a serious obstacle to socioeconomic development. Modern ecology politics has developed since the 1960 s, partly as a response to local environmental catastrophes such as smog in several towns in the United Kingdom and the pollution of the Great Lakes in the United States. Similarly, mercury poisoning came to be recognized as being due to contaminated fish in the food supply of Minimata and Niigata, Japan [1, 2]. Subsequently, systems to monitor acid rain and other toxic compounds were organized. This led to the development of different methods for achieving ecological normalization as a component of the life cycle impact assessment (LCA) methodology. Such an approach may offset similar environmental degradation tendencies in the developing world.

Ecological normalization, also called ecological standardization, is a process to enable the determination of the admissible levels of anthropogenic influence on the environment in order to restore nature by, for example, adoption of strategies to restore damaged ecological systems [3].

*Address correspondence to this author at the The School of Natural Sciences, Linnaeus University SE-391 82 Kalmar, Sweden;

Tel: +46 (0)480-446 721; Fax: +46 (0)480-447 340;

E-mail: william.hogland@lnu.se
A modern trend is the increasingly significant movement towards establishing voluntary agreements on environmental issues between industry and the authorities, as opposed to the imposition of centralized regulations. Generally, the main goal of the ecological normalization effort is to meet the combined societal, ecological and financial needs of the community. Traditionally, the standards of environment quality are those for air, water, noise and vibration [4]. The definitions for each limit vary between countries, but there is now a tendency for unification, for example, in the European Union [1].

European standards contain achievement indicators. Broadly speaking, such indicators are a means of measuring the fulfillment of goals considered to be desirable for environmental preservation or amelioration. When setting the standards, it is necessary to take into account the technological feasibility of their achievement as well as financial and political conditions in the country. Thereafter, the standards set must enable technical progress in order to allow the achievement of environmental goals within a reasonable time.

The three objectives of this study are:

(1) To examine the main stages and characteristics of the development of ecological normalization methods in the former USSR and Russia, in Europe, principally in the mainland European Union, and in the USA. 
These actors are, however, also engaged in global technological and industrial competition;

To introduce a classification of modern ecological normalization methods; and

To discuss the application of methods for the progressive development of ecological normalization.

\section{MATERIALS AND METHODOLOGY}

\subsection{General Methodology}

This paper reviews the history of, and the various methodologies adopted in, attempts to normalize the anthropogenic load. The time span of interest covers that of the present day environmental consciousness that arose mainly in the 1960s. The different approaches to problem solving, dependent upon the circumstances pertaining in the former USSR and present day Russia, as well as in Europe and in the USA, are emphasized.

An introduction touches upon the history of increasing environmental awareness in the East and West. Thereafter, the paper reviews the development of ecological normalization methods in these geographical areas.

The authors attempt to classify these methods and to forecast the implementation of future ecological normalization methods in Russia and Western countries. The results and discussion are followed by conclusions concerning the developments that led to the situation today. Finally, likely future developments are considered.

The research combines the study of an evaluation of the characteristics of the regions of study, and the development of theories and models based on accumulated knowledge. The paper seeks to apply an analytical approach using the positive rather than normative research process.

Secondary processed data in the literature are principally used in the descriptive investigation. A quantitative methodology is applied as, for example, by presenting recognized historical and sometimes numerical data to support the conclusions.

The results are considered to be valid due to the prevailing application of traditionally accepted normalization methods and their described historical development. An acceptable reliability is ensured by the use of relevant information from published scientific literature.

\subsection{Development of Ecological Normalization Methods}

Rachel Carson's book Silent Spring [5] first drew major attention to environmental issues. Following this publication, people became increasingly aware of the environmental drawbacks of modern society [6]. Environmental policies have developed rapidly during recent decades. In this section, this trend is first generally outlined and then studied in more detail.

\subsection{Historical Review}

The primary period of study of the topic, from the end of the 1960s until the first half of the 1980s, can be portrayed as the first stage of ecological politics with a global perspective.
The main means of control were administrative and legislative tools. Ecological politics was based on a unified complex approach to the organization of nature-protecting mechanisms. Sweden took the lead in the environmental movement up to the 1980s. However, differences in the approach prevailed in several countries.

Following Carson's alarm signal, the public became increasingly aware of the environmental effects being caused by the activities of modern society. As a result, the United Nations launched a series of international environmental conferences in Stockholm, 1972, Rio de Janeiro, 1992, and Johannesburg, 2002 [7-9]. These conferences, together with the resulting extensive and ongoing environmental debate, have put the environment on the global agenda as a major issue for the future.

At the beginning of the 1970s, the USA became the first nation to use ecological standards in the federal law on air quality and water quality (33 USC 1251-1376) [10]. In 1974 , Germany and Denmark became the first countries in Western Europe to introduce such standards [11].

In the USSR, the quality standards were stricter for several reasons other than those in the USA and Western Europe. However, these high standards were not always observed because the necessary legislative mechanisms did not exist. Essential laws were not enforced and hence there was no real control over the observance of the standards [12-14]. Maximum permissible discharge is an example of regulations made for a particular enterprise based on a maximum permissible concentration of contaminating substances on the border of a sanitary buffer zone. The requirement was easily bypassed by increasing the height of the chimneys and employing similar measures [3].

In the USA in the 1980s, a special feature in the structure of nature-protective financing was observed. It became obvious that after achieving the level of pollutant concentration defined by the environmental standards, a further decrease was not financially feasible.

New problems appeared that were connected with toxins being found that could have long term and cumulative contaminant effects [1]. Thereafter, the ecological strategy of the USA changed, aiming at reducing the sources of pollution rather than the pollutants per se. Hence, emphasis moved towards the prevention of pollution.

One result of this growing international development towards prevention policy was the introduction of so-called "compensation politics" $[10,15]$. This mechanism had the goal of giving a financial advantage to several enterprises in the same region, and it was accomplished through a flexible system of limits using the sale of ecological certificates [10]. In the mid-1980s, the US EPA took one further step towards the model of "the right to pollute". It allowed enterprises, whose emissions were less than defined by the standards, to "accumulate" the saved volumes of emissions as credits within the system. This method was introduced to encourage industrial enterprises to pollute below the existing standards in order to win saleable credits and hence to receive an addi- 
tional profit as, for example, by securing reduced carbon dioxide emissions.

The same approach can be observed in other countries. In the late 1980s, the second stage of nature-protective politics began. Various methods of ecological control have been adopted in different countries [1], and are described below.

\subsection{Ecological Normalization in Russia}

\subsubsection{General Chronology}

Ecological normalization in the former USSR involved the establishment of limitations to harmful compound concentrations in natural media such as air, water, soil, and foods [16, 17]. The Ministry of Health Protection of the USSR also defined norms for the maximal permissible levels (MPL) of physical influence with regard to noise, vibration, and electromagnetic and radioactive radiation. All these norms were based on the hygienic principles of environmental protection. Such approaches were very valuable in the 1960s-1980s and they are currently used in many countries $[12,14]$.

After 1979, the same approach was also used during evaluation of the permissible outlet of different industrial materials. The climatic and geographical factors together with the parameters of an object and the current load on the exploited territory were considered using this procedure. Note that the system of hygienic normalization is still used in Russia [13, 14]. According to the authors' experience, this approach is not environmentally friendly and cannot ensure the safety of the complex natural ecosystems.

When establishing norms for emissions, it is necessary to take into account the technological standards of emissions (TSE). TSE represent the characteristics of ecological safety of technological equipment or process. TSE are widely used outside Russia as, for example, in Byelorussia, and Kazakhstan. The existence of such norms makes the control of the air-protecting activity of a plant easier and allows development of a justified strategy to diminish the negative influence of a pollutant on the environment.

New and complex problems with the ecological normalization of the anthropogenic load on a regional and global scale have appeared, due to industrial development and the increased total mass of polluting substances. At the same time, a shift in emphasis from human health and safety towards environmental protection can be observed.

Studies made by Izrael at the Russian Academy of Sciences (RAS) concerning the estimation of the influence on nature of such pollutants as $\mathrm{NO}_{2}, \mathrm{SO}_{2}$ and $\mathrm{O}_{3}$ were the first in Russia. The forest ecosystem was chosen for investigation. The hypothesis of plant productivity not decreasing by more than $10 \%$ below that of the preindustrial period was accepted as a criterion $[18,19]$.

In 1983, the General Assembly of the United Nations established the Bruntdland Commission [20]. The purpose was to develop a long-term environmental strategy towards achieving sustainable development in the new millennium. The Bruntdland Commission intended to emphasize the dynamic tension between poverty and environmental concern
[21]. In the beginning of the 1990s, environmental effort focused on the Rio de Janeiro Conference (1992) where Agenda 21 was highlighted. This concept and the strategies towards sustainability are reported by Marques [22]. During the same decade, ecoefficiency began to be used as a term, as for example, by Schmidheiny [23]. This expression denotes activities that have economic value whilst continuously reducing their use of resources and the associated ecological impacts.

\subsubsection{Climate Change}

One factor strongly related to plant productivity is climate change or thermal pollution. This is related to the emission of so-called greenhouse gases. This issue is a major one, especially in the developed countries. Action has been taken at the highest political level. Using the Kyoto Protocol, the United Nations set compulsory standards for diminishing greenhouse gas emissions [9, 24] of the developed countries. It is necessary to note that some industrially developed countries, for example, the USA, did not ratify the protocol.

At the United Nations Climate Change Conference in Montreal on 10 December, 2005, agreements were reached on future critical steps to tackle the highlighted climate change issue. An agreement was reached on the compliance regime for the Kyoto Protocol and the associated committee with its enforcement and facilitative branches. This decision is intended to ensure that the parties to the protocol had a clear accountability regime in meeting their emission reductions targets [11]. Another approach to improve the environment, primarily aimed at the issue of climate change, sought to curb, for example, the shift of industry and employment away from Europe and to less developed regions pointed out by Hunkeler [25].

\subsubsection{Anthropogenic Influence of Normalization}

One less explored aspect of normalization of anthropogenic influence is connected with the direct transformation of natural ecosystems related to industrial metabolism. Influence of any technical objective on the environment begins with the alienation and transformation of a territory. During the period of industrial activity, humans have changed the relationship between the areas of natural and anthropogenically modified ecosystems. Regions with a high concentration of differing technogenic objects are usually regarded as unfavorable from an ecological point of view. This is seen to be because of serious changes in the areas' substance and energy flow due to activities such as logging and the drainage of marshes.

It is necessary to establish a maximum concentration of anthropogenic inputs in certain territories. Different approaches to the evaluation of this level have been developed [26-28].

It should be noted that when establishing a framework for ecological normalization, there must be a systematic method. The following main principles are used in this approach [29]:

(1) Guiding principle: preference for the long-term consequences for human society and nature as a whole set against the short-term interests of individual manufacturers; 
(2) Outstripping principle: the organization of investigations for the establishment of a norm must commence before the start of an anthropogenic influence;

Permission-level principle: the establishment of those critical values of anthropogenic load that can guarantee ecological safety; and

(4) Self-regulation principle: the observance of a balance between positive and negative ecological effects.

\subsubsection{Spatial Units}

The choice of a spatial unit of normalization is a very important issue for the establishment of permission limits for anthropogenic influences. There are three main approaches for the solution of the problem:

(1) Landscape approach;

(2) Drainage basin approach; and

(3) Combination approach, i.e., 1 and 2 combined.

(1) Landscape approach. As a result of landscape investigations by Polynov [30] and Sochava [31], a transfer from the separate index of environment conditions to a complex index started. The first steps in this direction were made by Alexandrova et al. [29] and Glazovskaya [32], the latter elaborating the special maps and presenting the division into districts of territory by probable self-cleaning intensity of ground, air and water.

This approach has been developed by Snakin et al. [33] and Bashkin et al. [34]. These scientists determined the basic factors of landscape sustainability and presented an estimation of the sustainability using a system of marks.

A landscape was chosen as a spatial unit of ecological normalization in the above-mentioned papers. However, this approach implies certain scientific considerations. At first, choice of a definite, which means one of a great number, of nature frontiers as a landscape boundary is obviously subjective $[17,35]$. Significant obstacles during realization of the landscape approach also appear due to the complexity of large-scale landscape investigations etc. [14].

It is also reasonable to consider not a separate landscape and a natural complex as a whole for ecological normalization $[36,37]$. In this case, a small drainage area can be chosen as a spatial unit for ecological normalization.

Drainage basin approach. Horton is the founder of the drainage basin approach. In the 1940s, Horton attracted attention to important hydrological and geographical roles of rivers and their watersheds. A watershed is an indivisible geosystem, which is formed by a one direction substance flow [38-40]. Watersheds often coincide with the boundary of different economies [41].

There are many other arguments of perceptiveness of the drainage basin approach for ecological normalization: (i) most watersheds have clear boundaries and they can be easily selected on a map; (ii) water and erosive etc. balances of substances are practically closed in the framework of a wa- tershed; (iii) the possibility of use of the clear classification of water systems, for example, the classification by HortonShtraler, and; (iv) the drainage basin approach is a perfect method for solution of different ecological conflicts, including international conflicts.

(3) Combination approach. According to the authors, a combined approach encompassing the abovementioned approaches is presently favorable. Natural territorial complexes are admeasured within river basins differing from each other by their physical and geographical features, for example, relief and soil. Then, both the anthropogenic impairment and the total catchment area of a river are estimated. That kind of thorough investigation gives accurate data while determining maximum permissible charge [42].

\subsubsection{Normalization System Character}

It is emphasized that the methods of ecological normalization considered here are the property of the distinct science groups that have developed them. These methods are used in scientific applications only and are not intended for practical application. Thus, the Russian state system for the normalization of anthropogenic influences basically remains old fashioned. The system is currently based on a concentration principle that emphasizes the norms of maximum permissible levels and the technological limits. Likely future changes to this system are considered below.

\subsection{Ecological Normalization in Europe and the USA}

\subsubsection{Standardization Effort History}

The International Organization for Standardization (ISO) was established as early as 1947 in order to promote the development of standards to facilitate the exchange of goods and services. In 1987, the ISO 9000 series established worldwide accepted measures of product quality. In 1990, the ISO 14000 series came as a development of environmental standards in environmental management systems (EMSs): environmental analysis; environmental auditing; environmental labeling; life cycle analysis; and terms and definitions. Both ISO 9000 and ISO 14000 are very popular among companies in Europe. The declaration of the Rio Summit was the first step in new environmental protection, which included open access to information, citizen participation, liability and compensation schemes for pollution damage, and environmental assessment. In later years, the work has been carried forward to make auditing a positive management tool for small and medium enterprises (SMEs) [23].

\subsubsection{The LCA Methodology}

Whereas the issue of setting norms in the former USSR mainly dealt with the sources of pollution, in the USA and a number of European countries, another more complex approach was applied. One of the most prominent examples of this is life cycle assessment (for LCA methodology, see, for example, Guinée and Jeroen [44]).

LCA is a method of analyzing and assessing the environmental impact of a material, product or service throughout its entire life cycle. LCA is regarded as the basis of detailed long-term aims [45]. 
The process of making an LCA, although it consists of several consecutive phases, is actually an iterative process. Results from later phases often force the analyst to return to earlier phases and make changes to, for example, the system boundary model or the problem formulation. LCAs are comparative studies of different products performing the same function, process alternatives or waste handling options. LCAs may be performed as absolute studies on individual products with the aim of performing an improvement analysis. This is a kind of comparison, because the present situation is compared with future alternatives [46].

As specifically regards the issue of sustainable development, societal LCA provides a means to investigate how policy and policy makers can be linked to this methodology [25]. The LCA methodology provides a valuable basis and tool to fulfill ecological normalization ambitions. The forthcoming role of LCA is likely to be based on, for example, the new ISO 14040 and ISO 14044 recommended to serve as core reference documents for the users and practitioners of LCA [47].

\subsubsection{Environmental Auditing}

Environmental concerns, growing public and media pressure and regulatory measures are changing the way people do business around the world. Consumers and shareholders are pushed by, for example, the media increasingly to demand environmentally friendly products and services. It is becoming increasingly important for certain organizations to demonstrate that not only their philosophies but also their investment strategies and day-to-day operations are sustainable.

Since the mid-1980s, global environmental accords have become significantly important. Environmental auditing is now an essential tool in sustainable national economic development. Auditing was introduced to create internal business and environmental risk management. This facilitated industrial performance, prevented pollution, corrected problems, conserved resources, reduced liability and improved community relations. The practice of environmental auditing refers back to the British Standard Institution 7750 and the EU Eco-Management and Audit Scheme (EMAS). EMAS is a management tool to enable companies and other organizations to evaluate, report and improve on their environmental performance. The scheme has been available for participation by companies since $1995[48,49]$ and was originally restricted to companies in the industrial sector [43].

Since 2001, EMAS has been open to all economic sectors including public and private services [50]. EMAS was additionally strengthened by the integration of EN/ISO 14001 as the EMS required by EMAS by adopting its attractive logo to signal EMAS registration to the outside world, and by considering strong indirect effects such as those related to financial services or administrative and planning decisions. Participation is voluntary and extends to public or private organizations operating in the EU and the European Economic Area (EEA), i.e., Iceland, Liechtenstein and Norway [51].

According to the 14001 EMS, a management system audit is a systematic, documented verification process. This includes the objective collection and evaluation of evidence for the purpose of determination as to whether an organization's EMS conforms to the audit criteria set by the organization. The results of this process are to be reported to management [52].

The process of implementation and use of the EMS is very similar for systems that are established in accordance with ISO 14001 and EMAS. However, there are some differences between these standards. The most significant difference is that EMAS requires a public environmental statement, whereas only a company environmental policy is public according to ISO 14001 [27]. Furthermore, there is a requirement for companies under ISO 14001 to consider external communication and record decisions. By the end of December 2005 , at least 111,162 certifications of ISO 14001 had been issued [52]. When performing an audit, the objective should be identified and agreed upon and the scope should be clearly understood [43] in terms of the following:

\section{Geographic region;}

Organizational context;

Specific area of the study;

Risk-associated area; and

Legal and regulatory standards.

\subsubsection{Identification of Potential Failure}

Examples of complex approaches in setting norms are the Failure Mode and Effects Analysis (FMEA) and the Failure Modes, Effects and Criticality Analysis (FMECA) methods. These are methodologies designed to identify potential failure modes for a product or process, to assess the risk associated with those failure modes, to rank the issues in terms of importance and to identify and carry out corrective actions to address the most serious concerns [53]. Although the purpose, terminology and other details can vary according to type, for example the Process FMEA and the Design FMEA, the basic methodology is similar for all.

Most analyses of this type also include some method to assess the risk associated with the issues identified during the analysis and to prioritize corrective action. Two common methods include [53]:

$$
\begin{aligned}
& \text { Risk priority numbers (RPNs); and } \\
& \text { Criticality analysis (FMEA with criticality analysis, } \\
& \text { i.e., FMECA). }
\end{aligned}
$$

There are a number of published guidelines and standards for the requirements and recommended reporting format of the FMEA and FMECA methods. Some of the main published standards for this type of analysis include SAE J1739, AIAG FMEA-3 and MIL-STD-1629A [53]. In addition, many industries and companies have developed their own procedures to meet the specific requirements of their products and/or processes.

The FMEA and FMECA analysis procedures are tools that have been adapted in many different ways for many different purposes. They can contribute to improved design for products and processes, resulting in higher reliability, better 


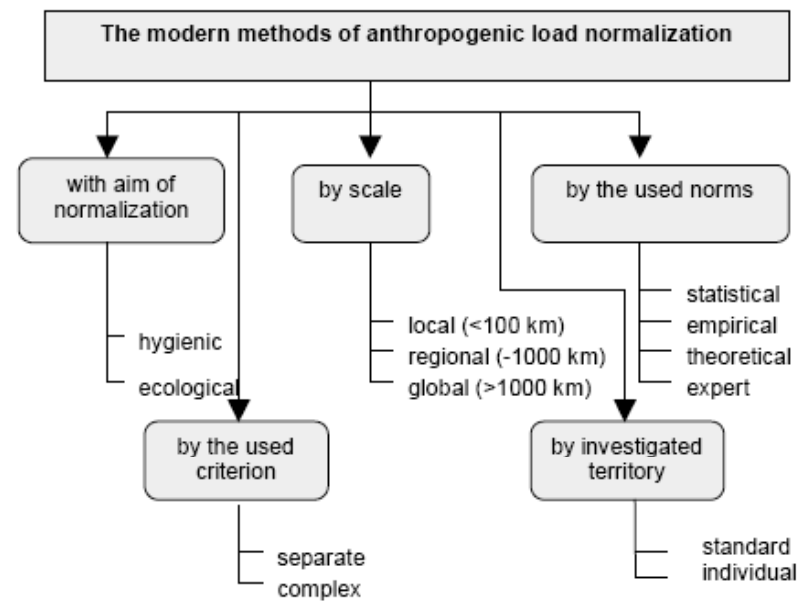

Fig. (1). Methods of ecological normalization of anthropogenic load.

quality, increased safety, enhanced customer satisfaction and reduced costs. The tools can also be used to establish and optimize maintenance plans for repairable systems and/or contribute to control plans and other quality assurance procedures. In addition, an FMEA or FMECA analysis is often required to comply with safety and quality requirements, such as are stipulated by regulations set out in ISO 9001, QS 9000, ISO/TS 16949, Six Sigma, FDA good manufacturing practices (GMPs) and the Process Safety Management Act (PSM).

\subsubsection{Classification of Ecological Normalization Methods}

Based on the previous statements, it is obvious that in a global context there are a great number of methods available to permit the normalization of anthropogenic load. A general classification of such methods is proposed for clarity (Fig. 1). In general, the methods of ecological normalization of the anthropogenic load can be classified by the:

Aim of normalization;

Criteria used;

(3) Spatial scale;

(4) Nature of the investigated territory; and

(5) Norms engaged.

The classification enables an expedient comparative analysis of various methods of normalization. However, with regard to the advantages and shortcomings of different methods, it is necessary to, among other things, consider group concerns. For example, it is impossible to compare methods of normalization that are distinguished by the scale or the nature of the investigated territory. This is because ecosystems of different levels have various mechanisms of stability $[34,35]$. The definition of the ecological norms of anthropogenic load for reserved territories [43] is also an independent task.

\subsubsection{Implementation of the Future Approaches of Ecological Normalization}

Progress in the implementation of ecological normalization methods follows the direction of the determination of a territorial ecological capacity and the extension of norms and standards for technological equipment and materials. The essence of the situation is as follows.

The Western countries have applied international ecological quality standards such as Euro-2 and Euro-3 for transport and forest management certification according to the Forest Stewardship Council. These standards demand correct ecological derivation of the products in question. At the same time, the rules of environmental protection in highly developed countries state that the process of manufacture of environmentally acceptable products should be safe for nature and the population in the territory where the manufacturing process is situated. Emissions must also meet international standard limits. To meet these requirements, the Western countries invest heavily and devise unique nature protection methods. Such measures make the production more expensive.

At the ISO session in October 2002, the head of the Russian State Standard Organization (Gosstandart), Boris Alioshin, stated that the law that would start the reformation of the Russian system of standards would soon be accepted. However, such laws still do not exist in Russia. Notwithstanding that, compliance with the international system of standards is generally considered necessary in order for the Russian Federation to join the World Trade Organization (WTO).

The foregoing implies that Russia is ready to abandon its national methods and forms of standardization in favor of the Western analogues because the Russian standards are not accepted by international organizations. Presently, only the state standards GOST R ISO 9001, 9002, 9003-96, GOST R ISO 9004-2001 and GOST R ISO 14001-98 are accepted in Russia. According to Alioshin [54], the reform will take 5-7 years and will in total cost Russia MUSD 25-30. The main restrictions on this transfer are, of course, financial, not ecological. However, the realization of this scenario, as well as Russia's entry into the WTO, is still absent.

\section{RESULTS}

1. Mathematical models were frequently used in the former USSR to establish permissive pollution levels, whereas in the Western world, environmental management tools are more emphasized as ecological normalization methods for industrial application.

2. Ecological normalization methods represent efficient management of public health and the environment.

3. A "cradle to the grave" approach is commonly applied in Western countries, for instance by the use of the LCA methodology, to accomplish ecologically acceptable production.

4. The framework for environmental standards and legislation is expected to be harmonized between Russia and the Western world. Russia is now undergoing a phase of development in ecological audit. Russian enterprise has access to international markets, and companies are obliged to carry out ecological audit procedures to obtain an internationally acceptable certifi- 


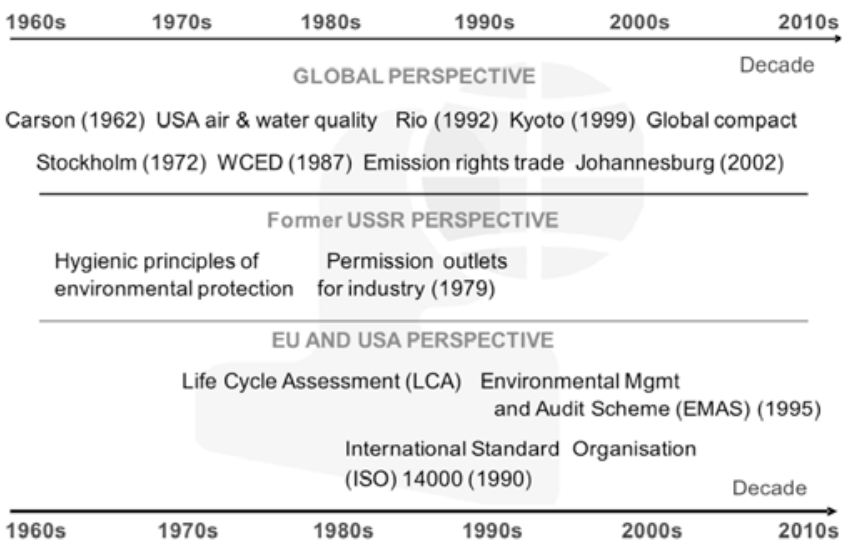

Fig. (2). Environmental management trends from the 1960s to present.

cate. This requirement promotes competitive ability if the manufacturing processes meet the EMAS and ISO 14000 standards. ISO 14000 is a so-called voluntary standard that is not a substitute for a legislative requirement for a system that detects the effect of company activity on the environment and its compliance with the law.

5. The development of ecological normalization methods will follow the unification of the quality standards for various countries as a complex approach.

\section{DISCUSSION}

During the 1960s and the 1980s in the former USSR, ministries set norms of maximum permissible levels of physical influence based on the hygienic principles of environmental protection. From the end of the 1970s, the same approach was also used during the evaluation of permission for outlets of differing industrial discharges. During the same period, a shift of emphasis was observed from human health and safety to environmental protection. The norm-setting theories encompassed approaches such as the following:

(1) Influence effect models;

(2) Anthropogenic energetic influences;

(3) Flow of environmental pollution;

(4) Thermodynamic calculations;

(5) Landscape approach;

(6) Drainage basin approach; and

(7) Combination approach.

Such promising approaches are not, however, reflected in the Russian Federation's ecological normalization system. When considering the current rapid change in the Russian economy and the entry of many Russian enterprises on the world market, changes can be expected in the present system of ecological normalization. Primarily, this development requires a transition from methods based on the concentration principle to approaches that specify the amounts of pollution per unit, for example per tonne, of developed production.
In Europe and the USA, on the other hand, widespread comprehensive standards for environmental management have been introduced, examples of such tools being under the headings of LCA, ISO and EMAS. Generally, the standardization efforts are more widespread and more broadly applied in the West than in the region corresponding to the former USSR.

This implies the existence of a certain trade barrier for Eastern European companies exporting to the West. Businessmen in the former region are less acquainted to compliance with such environmental standards. For example, Swedish and other foreign companies are obliged to receive corresponding Russian certificates for trade with Russia because of the existing differences between the requirements of Gosstandart and ISO. It is generally the individual enterprises and not government policy that mainly promotes the process of unification of standards between the East and the West.

The system of ecological audit in Russia is developing in the following ways:

(1) Activity in the market for nature conservation, which is subject to a certification procedure, has led to an improvement in the efficiency of procedures for environment quality assessment;

Environmental management audits developed through resources management, connected to the mining industry in particular. Targets for the audit system include other management spheres such as the geological authority and forest management; and

(3) Audit of territories and cities. This concern is poorly elaborated in Russia notwithstanding that many socioeconomic and ecological problems originate at the local and regional level.

In Fig. (2), the environmental management trend perspectives are summarized for the recent decades:

(1) Global;

(2) Former USSR; and

(3) EU and USA.

Measures have been taken locally to establish water, air and sewage management. At the global level, the commitments towards the reduction of CFCs and amelioration of the ozone depletion effect have been relatively successful. As regards health concerns, it may be argued that the lack of a direct or immediate connection with human health may have delayed or prevented similar action against activities that promote the alleged global warming. These examples suggest that control versus voluntary agreement and human health versus ecological management represent the fundamental categories of the debate. In reality, there is a considerable redundancy in the application of environmentally appropriate means and measures.

The "cradle to the grave" approach is commonly applied by, for example, the use of the LCA methodology, primarily in Western countries, to accomplish ecologically appropriate 
production. The prevailing ambition to meet international standard limits induces extensive investment in environmental care. This is said to make production more costly than it would otherwise be, particularly in the short-term perspective, but could possibly reduce external costs to public health and the environment.

A similar development can be expected in Russia where there is a need for compliance with internationally accepted environmental standards. This is necessary in order for Russia to be considered as a suitable candidate to join the major international trade network. A framework of mutually acceptable standards and legislation may be expected to be harmonized between Russia and the Western world.

Financial requirements significantly influence the choice of ecological normalization methods. It is not possible to be certain that ecological normalization methods accepted at state level will assure the sustainable function of ecosystems within the biosphere in the longer term.

The approaches made are tools that can be adapted in many different ways for varying purposes. They can be improved to promote, for example, both the environment and corporate profitability. A complex approach is hence needed to achieve a harmonization of different ecological normalization methods. For this reason, investigations in the direction presented here should be continued.

\section{CONCLUSION}

The choice of ecological normalization methods is significantly influenced by current financial requirements. In the long run, it is not possible to be certain that the ecological normalization methods that are accepted at the state level will assure the sustainable function of ecosystems within the biosphere. However, environmental efficiency is likely to be improved due to the use of an ecological normalization method giving rise to the environmental problem in question being favorably scrutinized.

The approaches made are to be viewed as tools that can be adapted in many different ways for varying purposes. Such approaches could be improved to promote the environment as well as the profitability of companies. Complex approaches enable a harmonization of different ecological normalization methods. Thus, investigations should be performed based on the findings presented here.

\section{ACKNOWLEDGEMENTS}

The authors are grateful to the Swedish Institute [Svenska Institutet], the Knowledge Foundation [KK-stiftelsen], and the Russian Foundation of Fundamental Researches (Project № 06-08-01432a) for providing financial support to enable the writing of this article.

\section{REFERENCES}

[1] F. N. Magill, Ed., Great Events from History II: Ecology and the Environment Series 2-5. Pasadena, CA: Salem Press, 1995.

[2] The Nature Conservancy, The Conservation of Biological Diversity in the Great Lakes Ecosystem: Issues and Opportunities. Chicago: Nature Conservancy, 1994.

[3] M. V. Romanov, "The main thesis of methodology for environmental normalization of anthropogenic load on the small drainage areas", J. Reg. Ecol., vol. 3-4, pp. 36-42, 1998 (in Russian).
The Government of Russian Federation, Federal Law on Environment Protection. Moscow: Standards Publisher, 2002 (in Russian).

[5] R. Carson, Tyst vår [Silent Spring]. Stockholm: Tidens förlag, 1963 (in Swedish).

[6] J. Stenis, "Industrial management models with emphasis on construction waste", Doctoral thesis, Lund University, University of Kalmar, Sweden, 2005.

[7] United Nations, "Report of the United Nations conference on the human environment 2003", Stockholm: 1972. http://www.unep. org/Documents.Multilingual/Default.asp?documentid=97 [AccessedJanuary 22, 2011].

[8] United Nations, "Rio declaration on environment and development. The United Nations conference on environment and development", Rio de Janeiro: 1992. http://www.unep.org/Documents.Multilingual/Default.asp?documentid $=78 \&$ articleid $=1163$ [Accessed January 22, 2011]

[9] United Nations, "Johannesburg Summit 2002. The World Summiton sustainable development", Johannesburg: 2002. http://www.johannesburgsummit.org/html/basic_info/basicinfo.htm 1 [Accessed January 22, 2011].

[10] US Environmental Protection Agency, "Clean Air Act 2002". http://www.epa.gov/air/caa/ [Accessed January 22, 2011]

[11] United Nations, "Framework convention on climate change (UNFCCC). Press release. United Nations climate change conference agrees on future critical steps to tackle climate change 2006". http://unfccc.int/files/press/news_room/press_releases_and_advisor ies/application/pdf/press051210_cop11.pdf [Accessed January 22, 2011].

[12] K. N. Dyakonov, "Methodological problems of investigations of the physical-geographical differentiation", Questions Geog., vol. 1, pp. 28-51, 1975 (in Russian).

[13] M. P. Fedorov, Ed., Ecological Basis for Management of NaturalTechnical Systems. St Petersburg: Publishing House of Polytechnic University, 2007 (in Russian).

[14] M. V. Romanov, Thermo Dynamical Approach for Explanation of Sustainable Development of the Natural-Technical Systems. St Petersburg: Publishing House of Polytechnic University, 2003 (in Russian).

[15] M. E. Kraft, Environmental Policy and Politics. Boston: Addison Wesley Longman, 2001

[16] Soviet State Standard (USSR GOST) 17.2.1.04-77, Nature Protection. Atmosphere. Sources and Meteorological Factors of Pollution, Industrial Emission. Moscow: Standards Publisher, 1977, 325 (in Russian).

[17] Soviet State Standard (USSR GOST) 17.2.3.02-78, Nature Protection Atmosphere Rules of Permissible Emissions Setting for the Industrial Enterprises. Moscow: Standards Publisher, 1979, pp. 5-47 (in Russian).

[18] Y. Izrael, L. Filippova, and G. Insarov, "Ecological effects of the environment pollution on global scale", Probl Ecol Monit Ecosyst Model. vol. 10, no. 10, pp. 10-22, 1987 (in Russian).

[19] E. Vainert, R. Valter, and T. Vetsel, Bioindication of Land Ecosystems Pollution. Moscow: Peace, 1988 (in Russian).

[20] United Nations, "Resolution 38/161: Process of preparation of the environmental perspective to the Year 2000 and beyond 1983". http://www.un.org/documents/ga/res/38/a38r161.htm [Accessed January 22, 2011]

[21] J. Robinsson, "Squaring the circle? Some thoughts on the idea of sustainable development", J. Ecol Econ. vol. 48, pp. 369-384, 2004

[22] M. Marques, "Concept and Strategies Towards Sustainability", in Key Areas of Environmental Entrepreneurships and Relevant Legal, Financial and Organizational Framework, S. Alriksson, M. Hakuli, P. Helo, W. Hogland, T. Kekäle, M. Kohtamäki, M. Marques, K. Paajaste, J. Peltoniemi and P. Peura, Eds. Prepared in frames of the TEMPUS-TACIS project IB_JEP-23100-2002 "Developing sustainable business pattern in Ukraine". 2006, pp. 284294.

[23] S. Schmidheiny, Changing Course. Boston: Massachusetts Institute of Technology Press, 1992.

[24] United Nations, Framework convention on climate change (UNFCCC), "Submissions from relevant intergovernmental organizations on their ongoing capacity-building activities 2000". http://unfccc.int/resource/docs/2000/sb/inf09.pdf [Accessed January 22,2011$]$. 
[25] D. Hunkeler, "Societal LCA methodology and case study", Int. J LCA. vol. 11, no. 6, pp. 371-382, 2006.

[26] A. M. Alpatiev and V. S. Jekulin, "About principles of biosphere protection and anthropogenic reorganizations of environment", Man Environ, 1977, pp. 18-21 (in Russian).

[27] V. G. Gorshkov, "Energetics of biosphere and environment sustainability", Totals Sci. Technol. vol. 7, pp. 125-136, 1990 (in Russian).

[28] M. V. Romanov and A. E. Tarakanov, "Elaboration of expertmodelling geoinformation system for complex ecological normalization of technogenic load at small drainage areas", in Third Youth Environmental Conference "Ecobaltica-2000", 2000, pp. 156-164 (in Russian).

[29] T. D. Alexandrova, N. Y. Lebedeva, and I. Y. Dolgushin, "The Normalization of Loads on Landscapes: Principles, Approaches, Methods", in: Sustainability and Variability as a Scientific Basis for Anthropogenic Loads Normalization. Moscow: 1988, pp. 5-8. (in Russian).

[30] B. B. Polynov, "Theory of landscape", Question Geogr. vol. 33, pp. 30-44, 1953 (in Russian).

[31] V. B. Sochava, Introduction to the Theory of Geosystems. Novosibirsk, Russia: Science, 1978.

[32] M. A. Glazovskaya, "Landscape-geochemical systems and its sustainability to technogenesis", Biogeochem. Cycles Biosphere. vol. 1, pp. 99-118, 1976 (in Russian).

[33] V. V. Snakin, V. E. Mel'nichenko, and P. O. Butovsky, Evaluation of Ecosystem's State and Sustainability. Moscow: Research Institute of Nature, 1992.

[34] E. V. Bashkin, V. N. Efstafieva, and V. V. Snakin, Biogeochemical Principles of Ecological Normalization. Moscow: Science, 1993.

[35] D. L. Armand, Science About Landscape. Moscow: Idea, 1975 (in Russian).

[36] L. M. Koritnii, "Drainage-basin approach in geography", Geogr. Nat Resour. vol. 1, pp. 161-166, 1991 (in Russian).

[37] B. V. Vorobiev and L. A. Kosolapov, Water Streams and Reservoirs: Relationship between Ecology and Economy. Leningrad: Hydrometeo Publishing House, 1987 (in Russian).

[38] R. S. Chalov, Ed., Work of Water Flows. Moscow: Moscow State University, 1987, pp. 9-32 (in Russian).

[39] A. V. Doncheva, L. K. Kazakova, and V. N. Kalutskov, Landscape Indication of Environment Pollution. Moscow: Ecology, 1992 (inRussian).

[40] P. Koval'chuk and R. S. Chalov, "Ecological-geomorphologic aspects of investigation of erosion-accumulation processes on different river basins in assimilation regions", Probl Erosion. River Bed Estuarial Evol, vol. 1, pp. 45-47, 1992 (in Russian).

[41] V. I. Struman, Principles of Ecological Map Making. Ijevsk, Russia: Udmurt University Publishing House, 1995.

[42] N. V. Arefiev, V. L. Badenko, and K. V. Zotov, Management of Natural-Technical Complexes: Introduction in Ecoinformation Sci- ence. St Petersburg: St Petersburg State Technical University, 2000 (in Russian).

[43] D. D. Nelson, International Environmental Auditing. Rockville, MD: Government Institutes, 1998.

[44] B. Guinée and B. Jeroen, Ed., "Handbook on life cycle assessment: Operational guide to the ISO standards series", in: Eco-efficiency in industry and science. vol. 2, pp. 1-708, 2002.

[45] S. Alriksson, "Eco-Management and audit schemes - EMAS, in S. Alriksson, M. Hakuli, P. Helo, W. Hogland, T. Kekäle, M. Kohtamäki, M. Marques, K. Paajaste, J. Peltoniemi, and P. Peura, Eds, Key Areas of Environmental Entrepreneurships and Relevant Legal, Financial and Organizational Framework, Prepared in frames of the TEMPUS-TACIS project IB_JEP-23100-2002 "Developing sustainable business pattern in Ukraine". 2006, pp. 391395 (in Russian and English).

[46] SETAC, Guidelines for Life Cycle Assessment: A Code of Practice. Brussels: Society of Environmental Toxicology and Chemistry, 1993.

[47] M. Finkbeiner, A. Inaba, and R. Tan, "The new international standards for life cycle assessment: ISO 14040 and ISO 14044”, Int. J. LCA. vol. 11, no. 2, pp. 80-85, 2006.

[48] European Economic Community, Council Regulation (EEC) No $1836 / 93$ of June 29,1993 , allowing voluntary participation by companies in the industrial sector in a community ecomanagement and audit scheme 1993.

[49] W. Hogland and M. Marques, "Environmental management systems" in S. Alriksson, M. Hakuli, P. Helo, W. Hogland, T. Kekäle, M. Kohtamäki, M. Marques, K. Paajaste, J. Peltoniemi, and P. Peura, Eds., Key Areas of Environmental Entrepreneurships and Relevant Legal, Financial and Organizational Framework, Prepared in frames of the TEMPUS-TACIS project IB_JEP-23100-2002 "Developing Sustainable Business Pattern in Ukraine". 2006, pp. 358-373.

[50] European Economic Community. Regulation (EC) No 761/2001 of the European parliament and of the council of March 19, 2001, allowing voluntary participation by organizations in a Community eco-management and audit scheme (EMAS) 2001.

[51] European Commission, "European Union, Eco-management and audit scheme (EMAS), 2001". http://ec.europa.eu/environment/emas/index_en.htm [Accessed January 22, 2011].

[52] Swedish Standards Institute 2007. http://www.sis.se/DefaultMain.aspx [Accessed January 22, 2011].

[53] ReliaSoft Corporation, "Failure modes, effects and criticality analysis 2005". http://www.weibull.com/basics/fmea.htm [Accessed January 22, 2011].

[54] Open Economy, "A reform of domestic system of standards will begin in "Russia 2002" (in Russian). http://www.opec.ru/news_doc.asp?tmpl=news_doc_print\&d_no=3 0175 [Accessed January 22, 2011].

(C) William Hogland; Licensee Bentham Open.

This is an open access article licensed under the terms of the Creative Commons Attribution Non-Commercial License (http://creativecommons.org/licenses/by-nc/3.0/g) which permits unrestricted, non-commercial use, distribution and reproduction in any medium, provided the work is properly cited. 